Joint Irish Section and American Society for Nutrition Meeting, 15-17 June 2011, 70th anniversary: 'Vitamins in early development and healthy ageing: impact on infectious and chronic disease'

\title{
Sodium (Na) intakes in Irish adults
}

\author{
M. Giltinan ${ }^{1}$, J. Walton ${ }^{1}$, B. McNulty ${ }^{2}$, A. Nugent ${ }^{2}$, M. Gibney ${ }^{2}$ and A. Flynn ${ }^{1}$ \\ Irish Universities Nutrition Alliance (IUNA) at: ${ }^{1}$ School of Food and Nutritional Sciences, University College Cork, \\ Cork, Republic of Ireland and ${ }^{2}$ UCD Institute of Food and Health, University College Dublin, Belfield, Dublin 4, \\ Republic of Ireland
}

$\mathrm{Na}$ intakes from food sources (i.e. excluding $\mathrm{Na}$ in salt added in cooking or at the table) were estimated using data from the National Adult Nutrition Survey (NANS). The NANS was carried out between October 2008 and April 2010 to establish a database of habitual food and drink consumption in a representative sample of Irish adults $(n 1500)$ aged 18 years and over. A 4-d semi-weighed food record was used to collect food intake data. Dietary intake data were analysed using WISPC (Tinuviel Software, Anglesey, UK), which is based on the sixth edition of McCance and Widdowson's The Composition of Foods ${ }^{(1)}$ and the Irish food composition database ${ }^{(2)}$. Underreporters were excluded from the analysis.

\begin{tabular}{|c|c|c|c|c|c|c|}
\hline & \multicolumn{3}{|c|}{ 18-64 years } & \multicolumn{3}{|c|}{$\geq 65$ years } \\
\hline & All $(n 889)$ & Males $(n 448)$ & Females $(n$ 441) & All $(n$ 162) & Males $(n$ 75) & Females $(n$ 87) \\
\hline Salt intake & $\mathrm{g}$ & $\mathrm{g}$ & $\mathrm{g}$ & $\mathrm{g}$ & $\mathrm{g}$ & $\mathrm{g}$ \\
\hline Mean & 7.4 & $8.5^{*}$ & 6.2 & 6.3 & $7.3 *$ & 5.4 \\
\hline SD & 2.4 & 2.3 & 1.8 & 2.3 & 2.6 & 1.5 \\
\hline Median & 7.1 & 8.4 & 6.0 & 5.9 & 7.3 & 5.4 \\
\hline \multicolumn{7}{|l|}{ Percentiles } \\
\hline 5th & 3.9 & 4.9 & 3.4 & 3.1 & 3.3 & 3.0 \\
\hline 95th & 11.6 & 12.6 & 9.3 & 10.6 & 12.0 & 7.7 \\
\hline
\end{tabular}

\begin{tabular}{|c|c|c|c|c|}
\hline \multirow[b]{2}{*}{ Food group } & \multicolumn{2}{|c|}{ All 18-64 years $(n$ 889) } & \multicolumn{2}{|c|}{ All $\geq 65$ years $(n 162)$} \\
\hline & $\mathrm{Na}(\mathrm{mg} / \mathrm{d})$ & $\%$ & $\mathrm{Na}(\mathrm{mg} / \mathrm{d})$ & $\%$ \\
\hline Meat and fish & 911 & 30.1 & 769 & 30.2 \\
\hline Cured/processed meats & 568 & 18.1 & 486 & 18.2 \\
\hline Meat/meat dishes & 248 & 8.6 & 163 & 7.0 \\
\hline Fish/fish dishes & 95 & 3.3 & 119 & 4.9 \\
\hline Bread and rolls & 630 & 21.9 & 617 & 24.8 \\
\hline Soups, sauces and miscellaneous foods & 254 & 8.5 & 223 & 8.7 \\
\hline Milk and milk products & 239 & 8.3 & 209 & 8.7 \\
\hline Vegetable/processed vegetables including potatoes & 205 & 7.0 & 135 & 5.8 \\
\hline Biscuits/cakes/pastries/confectionery & 180 & 6.3 & 117 & 4.9 \\
\hline Breakfast cereals & 171 & 5.7 & 155 & 6.0 \\
\hline RTEBC & 137 & 4.7 & 81 & 3.4 \\
\hline Other & 34 & 1.0 & 75 & 2.6 \\
\hline Spreading fats & 94 & 3.2 & 137 & 5.3 \\
\hline
\end{tabular}

Mean daily salt $(\mathrm{g})$ intakes in adults aged $18-64$ and $\geq 65$ years exceeded the FSAI salt intake target $(6 \mathrm{~g} / \mathrm{d})^{(3)}$. These estimates do not allow for all additions in cooking or any additions at the table, generally assumed to be about 15-20\% of total dietary Na intake. Meat and fish (especially cured/processed meats) and bread and rolls were the main contributors to Na intake.

Even when discretionary salt intake is excluded, mean salt intake of Irish adults exceed current FSAI salt targets.

The project was funded by the Department of Agriculture, Fisheries and Food under the Food for Health Research Initiative.

1. Food Standards Agency (2002) McCance and Widdowson's The Composition of Foods, 6th ed. Cambridge: Royal Society of Chemistry.

2. Black LJ, Ireland J, Møller A et al. (2011) Development of an on-line Irish food composition database for nutrients. J Food Compost Anal (In the Press) doi:10.1016/j.jfca.2011.01.015

3. Food Safety Authority of Ireland (2005) Salt and Health: Review of the Scientific Evidence and Recommendations for Public Policy in Ireland. Dublin:

Food Safety Authority of Ireland. 